The ripple-marks left by undulating waters

On limestones in Lake Killarney, and other quarters, May still be seen in progress.

Yours faithfully, A Subscriber.

\title{
6th August, 1862.
}

[If our correspondent is not pleased with his communication being set up by our compositor as a poetical effusion, he has no one to blame but himself; for, not sending us, in confidence, his name and address, we could neither send him a proof nor ask his instructions. We are continually annoyed by this reprehensible conduct, and many things worth printing are often, for this reason, consigned to our waste-paper basket. The post-mark on this communication is Ryde, but we should only give the Dead Letter officers trouble if we posted a letter "To Subseriber" there. It would be a worse address than the memorable "John Smith, England."-Fin. GEoL.]

\section{The Kirkdale Cavern.}

Sir,- In the September number of 'Macmillan's Magazine ' there is an article by Mr. Jolin Taylor, concerning this place, upon which, as I take it to be a very important one (thus greatly differing from the majority of geological papers, which are combinations of the most obvious facts and the most unobvious speculations), I am desirous of making a few observations. That it presents an agreeable contrast to the views of some of "our best authorities" in geology, no candid person can but admit; but, at the same time, I look upon it as perhaps the commencement of new inquiries, which probably will effect the demolition of similar irrational and far-fetched explanations.

That any individual could consider the one in question, and yet maintain the doctrine of Buckland, could, I think, only be accounted for on the ground of faith in this distinguished geologist,- the facts alluded to by Mr. Taylor being absolutely crucial as regards the conclusion drawn from them. We have here an example of an apparently geological phenomenon which is really an historical one, and of the utility which the knowledge of ancient customs is in the explanation of physical phenomena. In the present case, without this knowledge the explanation would have been only a speculation; but as the explanatory circumstance is known to have been a fact, and it is not possible otherwise to account for the phenomenon, there is as much certainty as can be obtained concerning any unseen phenomena. In this sense the conclusion is warranted, or crucial, from the facts brought forward. I have here, of course, presumed that the alleged facts are such, concerning which, as far as I can understand, no discussion can be raised.

\section{J. Alexander Davies.}

[We are sorry to read the opinion formed by our correspondent of the antiquated, absurd, and ignorant article in 'Macmillan's Magazine.' Want of space prevents comments on our part non it in the present number, but we shall refer to the subject again. Two excellent articles in the 'Londou Revicw' may, in the interim, be perused with advantage by Mr. Davies and those who concur in his appreciation of Mr. Taylor's untenable article.]

\section{GEOLOGICAL NOTES IN THE GREAT EXHIBITION.}

ITALY.-The Natural History Museum of the Royal University of Pisa exhibits the following plaster and wax models of fossils :-Mastodon Avernensis (jaws and separate teeth); Elephas meridionalis (jaws, part of upper jaw, teeth); Hippopotamus major (part of jaw, teeth); Rhinoceros Etruscus (skull, part of jaw, part of upper jaw); Lutra Campani (almost 